\title{
EL LAWFARE EN ARGENTINA: LUCHAS POR LA HEGEMONÍA DEL PODER EN EL CAMPO JURÍDICO
}

The Lawfare in Argentina: struggles for the hegemony of power in the legal field Revista de Direito Administrativo e Infraestrutura | vol. 9/2019 | p. 231 - 258 | Abr Jun / 2019

DTR $2019 \backslash 31961$

Pablo Octavio Cabral

Facultad de Ciencias Jurídicas y Sociales de la Universidad Nacional de La Plata (UNLP). Especialista en Derecho Administrativo (UNLP), docente de las facultades de Ciencias Jurídicas y Sociales y Periodismo y Comunicación de la Universidad Nacional de La Plata. Editor Ejecutivo de la Revista Derechos en Acción ([www.revistas.unlp.edu.ar/ReDeA]) y Director de Relaciones con el Sector Público de la Secretaría de Relaciones Institucionales de la Facultad de Ciencias Jurídicas y Sociales (UNLP). Abogado. pablooctaviocabral@yahoo.com.ar

Área do Direito: Constitucional

Resumen: En el presente trabajo se abordará un fenómeno político social que impacta en las ciencias jurídicas, proponiendo una mirada desde las ciencias sociales. Se trata de la judicialización de la política y del lawfare, intentando la comprensión de la relación existente entre el poder político y el campo jurídico, a partir de la utilización de las categorías teóricas de Pierre Bourdieu (espacio social, campo social, campo jurídico, habitus, illusio, capital jurídico, efecto simbólico, efecto de desconocimiento). Desde tal óptica se abordará el derecho administrativo argentino y su mirada a las relaciones de poder. Se intentará esbozar una respuesta a la pregunta: ¿Cuál es la relación entre el campo de poder y el campo jurídico en el actual gobierno en la Argentina? Para ello desarrollaré una hipótesis estructuralista -relación de los campos de poder y jurídico-, junto con una explicación constructivista -falta del habitus propio del campo jurídico por parte de los principales funcionarios del Poder Ejecutivo-.

Abstract: The present work will consider a social political phenomenon that impacts on the legal sciences, proposing a view from the social sciences. It is about the judicialization of politics and lawfare, trying to understand the existing relationship between political power and the legal field, starting from the use of the theoretical categories of Pierre Bourdieu (social space, social field, legal field, habitus, illusio, legal capital, symbolic effect, effect of ignorance). From this point of view, Argentine administrative law and its view of power relations will be addressed. An attempt will be made to outline an answer to the question: What is the relationship between the field of power and the juridical field in the current government in Argentina? For this I will develop a structuralist hypothesis - relation beetween the fields of power and juridical-, together with a constructivist explanation -lack of the proper habitus of the juridical field from the main officials of the Executive Power-.

Palabras claves: Judicialización de la política - Lawfare - Pierre Bourdieu - Campo jurídico - Neoliberalismo - Derecho administrativo

Keywords: Judicialization of politics - Lawfare - Pierre Bourdieu - Juridical field Neoliberalism - Administrative law

\section{Inicio}

Intentaré reflexionar sobre algunos fenómenos sociales que estamos viviendo en nuestro país y en la región, que repercuten en las instituciones jurídicas y en la realidad política de nuestros tiempos. Existe una explícita presión mutua -y confusión- entre las esferas de la política y los ámbitos procesales en los que el derecho tradicionalmente resuelve los conflictos ante imparciales jueces y bajo el cumplimiento y sometimiento a sus propias reglas, justificando así su autonomía científica e independencia institucional. Este 
fenómeno, conocido como judicialización de la política, o su contracara, politización de la justicia, adquiere actualmente en nuestro continente una modalidad más sofisticada y preocupante por sus consecuencias negativas que impactan de lleno en las bases del sistema democrático; el lawfare ${ }^{1}$. Detrás de él se vislumbra una tensión entre el poder ejecutivo (actor relevante del campo de poder) y el poder Judicial (actor central del campo jurídico). El derecho administrativo aborda en su objeto de estudio estas relaciones, ocultando muchas veces las relaciones de poder que intervienen en el campo jurídico.

La utilización de instrumentos jurídicos para fines de persecución política o la guerra jurídica consiste en la utilización de sectores del poder judicial con fines claramente de persecución política. Para que ello sea posible se requiere no solo de jueces cómplices, sino también de medios masivos de comunicación que actúen coordinadamente con esos objetivos. La guerra jurídica es un arma diseñada para destruir al enemigo mediante el uso, mal uso y abuso del sistema legal y los medios de comunicación para provocar protestas públicas contra ese enemigo. Es preocupante que, maniobras como éstas bajo apariencias de legalidad y de justicia lesionen seriamente la calidad democrática en nuestros países.

Existe -por lo general- en nuestras facultades de derecho una fuerza inercial endogámica que nos lleva a mantener nuestro objeto de estudio estático, sin percibir sus transformaciones o cambios, ni reconocer sus vinculaciones con otras realidades sociales. Ejemplo de ello es que, en nuestro país, durante largos períodos de tiempo en los que no regía el Estado de Derecho, por imposición antidemocrática de gobiernos dictatoriales que se sucedieron desde aquel triste 6 de septiembre de 1930, en nuestras escuelas universitarias de derecho se dictaron materias como derecho constitucional o derecho público provincial, en momentos en los que las constitución nacional y cartas magnas locales no estaban vigentes. En igual sentido, al estudiar el derecho administrativo se explicaba el principio de legalidad y la división de poderes; en derecho penal se desarrollaban las garantías del debido proceso; en el derecho laboral se explicaba el derecho a huelga, a la sindicalización y los principios protectorios del trabajador.

Este comportamiento -que podría ser considerado a priori desconcertante- puede hallar explicación en el concepto de illusio propuesto por Bourdieu para entender lo que sucede en el campo jurídico, que llevó a este pensador a definir a los juristas como los guardianes de la hipocresía colectiva y a destacar que existe una vinculación entre la pertenencia a las facultades de derecho y la orientación política hacia las posturas de derecha.

Resulta entonces necesario proponer un abordaje que permita un distanciamiento del enfoque jurídico tradicional que puso énfasis en el estudio y construcción de un cuerpo de doctrinas y de reglas totalmente independiente de sujeciones y presiones sociales. Un nuevo estudio que observe al derecho, por un lado, desde las relaciones de fuerza específicas que le confieren su estructura y que orientan las luchas de concurrencia y, por otro lugar, reconociendo la lógica interna de las obras jurídicas que delimitan en cada momento el espacio de lo posible, y por consiguiente, el universo de soluciones propiamente jurídicas.

Para intentar un inicial acercamiento alternativo a estos fenómenos recurriré a las enseñanzas de un teórico de las ciencias sociales, Pierre Bourdieu, quien -desde la sociología- destaca que, si bien la sociedad no se transforma por decreto, tampoco se debe olvidar que ser consciente de las condiciones sociales que determinan la eficacia de los actos jurídicos no debe conducirnos a ignorar o a negar la eficacia propia de la regla, del reglamento o de la ley. (Bourdieu y Teubner, 2000, p. 200).

II. Derecho y política 
El derecho, en su carácter instrumental e histórico, tiene por objeto esencial imponer en la sociedad un régimen determinado de ordenación y constituye en sí mismo un conjunto de reglas que fuerzan a un orden dado de la sociedad y sus miembros. El conjunto de reglas jurídicas obligatorias -histórica y geográficamente situadas-, integra un sistema abierto que se relaciona con el sistema institucional, político y social, y lo que el derecho aporta a la sociedad constituye sólo el medio para que se alcance un determinado orden social.

Entiendo que, si bien el derecho no puede reducirse a la política, sí es una actividad marcadamente impregnada de ella y en el caso del derecho público -campo en el que dirime las competencias de los poderes constituidos- esa influencia se encuentra más acentuada y por ello, al estudiar su funcionamiento, no se puede pretender teorizar aisladamente de esta realidad social que condiciona la extensión de su estructura y límites. La explicación jurídica queda incompleta sin referencia a su inspiración política y económica.

Una determinada conformación económica, política y social de la comunidad señala las ideas directrices y lineamientos de la organización estatal, operando el derecho como apoyo formal de esas ideas y cumpliendo la función de obtener la observancia de las normas que permitan hacerlas realidad. La concepción de lo que deben ser el poder judicial y el gobierno, sus estructuras y disposiciones internas, sus funcionamientos en la sociedad y las competencias de sus miembros se deciden en el espacio socio político y no únicamente dentro del campo jurídico.

El análisis del objeto de estudio no puede abordarse únicamente desde el aspecto jurídico formal, prescindiendo de las ideas políticas y económicas que influyen en la conformación de las normas e instituciones aplicables, y afirmando la autonomía absoluta de la forma jurídica en relación al mundo social. Una explicación del derecho que prescinda de tales doctrinas políticas y económicas, las que al incorporarse en una sociedad determinada inspiran y modelan su derecho, quedaría incompleta desde un punto de vista vital, porque aparecería como un conjunto sistematizado de normas vacías, aptas para cualquier solución posible. No obstante ello, el derecho tiene un funcionamiento interno propio que se interrelaciona con el contexto social e influye, a su vez, sobre las ideas políticas y económicas que se tienen sobre la organización de la sociedad.

\section{Explica Pierre Bourdieu que:}

"El derecho es la forma por excelencia del discurso activo, capaz, por su propia virtud, de producir efectos. No es exagerado decir que el derecho hace el mundo social, pero con la condición de no olvidar que él es hecho por ese mundo" (Bourdieu, 2001: 202).

Resulta necesario percibir ambos aspectos de la realidad, por un lado el sistema jurídico, con sus normas, doctrinas, jurisprudencia y teorías y por el otro los factores políticos, ideológicos, sociales y económicos que influyeron y fueron influidos por el derecho.

Afirmó Bourdieu que:

"Las prácticas y los discursos jurídicos son, en efecto, el producto del funcionamiento de un campo cuya lógica específica está doblemente determinada: por una parte por las relaciones de fuerza específicas que le confieren su estructura y que orientan las luchas de concurrencia 0 , más precisamente, los conflictos de competencia que tienen lugar en el derecho y, por otra parte, por la lógica interna de las obras jurídicas que delimitan en cada momento el espacio de lo posible $y$, por consiguiente, el universo de soluciones propiamente jurídicas [...]. La autonomización (del derecho) pasa, no por un reforzamiento del cierre sobre sí mismo de un cuerpo consagrado a la lectura interna de textos sagrados, sino por una intensificación de la confrontación de los textos y los procedimientos con las realidades sociales consideradas para expresarlas y regularlas" (Bourdieu, 2001: p.168). 
Veamos algunas de las ideas centrales de este sociólogo respecto del derecho para intentar realizar un acercamiento a los fenómenos y problemas descriptos como el objeto de nuestro interés: campo, espacio social, capital social, capital económico, capital cultural, capital jurídico, capital simbólico, habitus, violencia simbólica, objetivación, illusio, efecto simbólico, desconocimiento.

\section{El concepto de campo jurídico en la sociología de Pierre Bourdieu}

Pierre Bourdieu analiza la sociedad desde una perspectiva estructuralista y constructivista a la vez, superando la oposición entre subjetivismo y objetivismo en la ciencia social. Así explica García Inda que:

"para superar esa disyuntiva canónica entre la reducción de la historia a un proceso sin sujeto o su sustitución simplista por un sujeto creador, Bourdieu propone tomar como esquema para el análisis social la dialéctica de las estructuras objetivas y las estructuras incorporadas; o más concretamente, la relación dialéctica de las estructuras y los habitus." (Bourdieu- Teubner, 2000, p. 63).

Así, se propone dejar de lado las manifestaciones del pensamiento dualista que se traduce en pares de conceptos antagonistas, cuyos ejemplos respecto del derecho lo encontramos entre las teorías de Kelsen y Marx.

El concepto de campo social para Bourdieu refiere a un espacio social específico en el que las relaciones se definen de acuerdo a un tipo especial de poder o capital específico detentado por los agentes que entran en lucha o en competencia. El campo se encuentra determinado por la existencia de un capital común y la lucha por su apropiación. Para García Inda el campo social se entiende así como una "construcción analítica mediante la que designar un conjunto específico y sistemático de relaciones sociales; es decir, se trata de una especie de sistema, definible sólo históricamente, que permite trasladar al análisis social la dinámica de relaciones que se desarrollan en la práctica" (Bourdieu, 2001, p. 14).

Bourdieu identifica diversos campos sociales (económico, cultural, artístico, académico, sociológico, etc.), entre los que se encuentra el campo jurídico, pero entre los que se destaca por sus relaciones con el resto de los campos el campo de poder, caracterizado como un "campo de fuerzas definido en su estructura por el estado de la relación de fuerza entre las formas de poder o las diferentes especies de capital". (BourdieuTeubner, 2000, p. 68).

El concepto de habitus, puede resultar claro de la lectura de la explicación que el propio Bourdieu nos da:

"las estructuras que son constitutivas de un tipo particular de entorno (v.g. las condiciones materiales de existencia de un tipo particular de condición de clase) y que pueden ser asidas empíricamente bajo la forma de regularidades asociadas a un entorno socialmente estructurado, producen habitus, sistemas de disposiciones duraderas, estructuras estructuradas predispuestas a funcionar como estructuras estructurantes, es decir, en tanto que principio de generación y de estructuración de prácticas y representaciones que pueden ser objetivamente reguladas y regulares sin ser en nada el producto de obediencia a reglas, objetivamente adaptadas a su finalidad sin suponer la mirada consciente de los fines y la maestría expresa de las operaciones necesarias para alcanzarlas $y$, siendo todo eso, colectivamente orquestadas sin ser el producto de la acción organizadora de un jefe de orquesta". (Bourdieu, 2001: p. 30)

Como explica Carlos Morales de Setién Ravina, en la teoría en estudio, el concepto de capital cumple un rol central: "El capital es la finalidad del juego, del que Bourdieu distingue tres formas propias: capital económico, capital social y capital cultural. Cualquiera de estas formas, como explicaremos, puede adquirir la forma de capital simbólico". (Bourdieu- Teubner, 2000, p. 63). 
El derecho, desde la visión de Bourdieu, debe ser abordado partiendo del rechazo a la alternativa de calificarlo como ideología o como ciencia. Propone abandonar la pretensión universalista de los juristas construida sobre una norma fundamental y afirma que el derecho puede estar fundamentado únicamente en la historia y en la sociedad. Sostener que el derecho es una ideología, es perder de vista la lógica y el efecto específicos del derecho y nos impide percibir que, en su coherencia de sistema de leyes, es producto de un prologado trabajo de producción de coherencia, de racionalidad, realizado en un espacio particular que el autor denomina campo jurídico (Bourdieu, 2016). Según explica García Inda, para Bourdieu el derecho es el resultado de las luchas que se desarrollan entre agentes especializados, en competencia por el monopolio jurídico, esto es, en concurrencia por el derecho a decir qué es lo que dice el derecho (Bourdieu, 2001).

El campo jurídico es definido por Bourdieu como un universo social relativamente independiente en relación a las demandas externas, al interior del cual se produce y se ejerce la autoridad jurídica, forma por excelencia de la violencia simbólica legítima cuyo monopolio pertenece al Estado y que puede servirse del ejercicio de la fuerza física. Es decir, el campo jurídico "no es lo que se cree ser, es decir, un universo limpio de toda componenda con los imperativos de la política o de la economía. Pero el hecho de conseguir hacerse reconocer como tal contribuye a producir unos efectos sociales absolutamente reales, y, en primer lugar, sobre aquellos cuya profesión consiste en interpretar las leyes y establecer jurisprudencia". (Bourdieu- Teubner, 2000).

Así, puede pensarse como una parte del espacio social en la que los distintos agentes pelean por el monopolio para decir qué es el derecho, es el lugar donde abogados, jueces, profesores, funcionarios públicos, personas que ocupan una posición con respecto al campo general del poder y al interior de cuyas profesiones se reproduce también, se lucha, compiten entre sí, para determinar cuál es la autoridad que permite, en última instancia, decir qué es derecho.

El campo jurídico se caracteriza por ser un espacio limitado de lucha definido mediante regularidades de conductas y reglas aceptadas y en donde la distribución de la fuerza es desigual. Presenta momentos de crisis coyunturales donde las reglas que hasta ese momento venían regulando el juego se cuestionan.

Dentro de este campo, el capital cultural que juega un importante rol es el capital jurídico, que - según Bourdieu:

"se encuentra reforzado por el capital social que está en manos de los juristas por la posición relativa del campo jurídico al interior de la sociedad, pero también porque los participantes en el campo jurídico tienen, en muchas ocasiones, capital social proveniente de la correspondencia entre sus posiciones en el campo jurídico y las posiciones que ocupan en el campo social. Ese capital jurídico toma la forma de capital simbólico en muchas ocasiones: el capital simbólico se crea cuando una forma de capital se reconoce mediante categorías de percepción que reconocen su lógica específica 0 , si se prefiere, como el desconocimiento de su arbitrariedad en su posesión o acumulación" (Bourdieu- Teubner, 2000).

Por último explicaremos un concepto de illusio, central de la formación de los juristas, como actores principales del campo jurídico, obligados para su aceptación en el campo a creer en el juego y conceder al juego que merece ser jugado, que vale la pena.

Explica que:

"para conseguir este efecto de legitimación hay que pagar un precio, y los juristas son de algún modo las primeras víctimas de su propia creación jurídica. Tal es el sentido de la illusio: sólo hacen creer porque ellos mismos creen. Si contribuyen a la influencia del derecho es porque ellos mismos han caído en la trampa, en particular al final de todo el trabajo de adquisición de la creencia específica en el valor de la cultura jurídica, trabajo que es extraordinariamente importante para comprender el efecto que va a ejercer el 
derecho no solamente sobre los justiciables sino también sobre quienes ejercen el derecho" (Bourdieu, 2016: 1).

La construcción del hábito del jurista implica un arduo trabajo, principalmente desarrollado por las universidades que los forman y extienden sus títulos habilitantes, que además de transmitirle los contenidos del ordenamiento jurídico, también inciden en la adquisición de una postura física, corporal, de magistrado, combinación de ascesis, de reserva y de todo un conjunto de virtudes que son la materialización en disposiciones corporales de leyes fundamentales del campo jurídico como espacio autónomo de las constricciones externas. Ello llevo a Bourdieu a afirmar que los juristas, son los guardianes de la hipocresía colectiva.

Así, el abordaje del fenómeno en análisis presupone estudiar descriptiva y analíticamente la relación existente entre las diversas teorías éticas sobre la justicia, enmarcadas en las correspondientes corrientes ideológicas, políticas y filosóficas -campo político- y su vinculación con la construcción del derecho-campo jurídico-. Parto para ello de la afirmación teórica que sostiene que ambas cuestiones se desarrollan en diferentes campos, el ideológico/político y el jurídico pretendiendo indagar en tales relaciones y en las que se entablan con el campo de poder y que llevan a materializar determinadas políticas económicas, sociales e institucionales.

El derecho público, parte integrante o sub-campo dentro del campo jurídico, se construye a partir de una mirada ideológica sobre las relaciones entre los individuos y el poder público, en el que se desequilibran derechos y potestades conformando un sistema llamado "Estado de Derecho". Esta regulación normativa (constitucional, legal y reglamentaria) así como la construcción doctrinaria y jurisprudencial realizada en su entorno aplican y enmarcan criterios de distribución de bienes comunes, públicos y privados entre los ciudadanos a partir de la regulación estatal, poniendo en juego estándares de justicia distributiva. Aun cuando esto es así, existe un ocultamiento de esta relación entre ideología política y el campo jurídico ya que los agentes que actúan a su interior lo hacen -con el convencimiento que se les exige para pertenecer al campo jurídico- bajo el presupuesto de obedecer a verdades y valores trascendentes y universales, alejados de las componendas políticas y de los intereses económicos.

Es preciso aquí incorporar la herramienta conceptual llamada efecto de desconocimiento, entendido como el conjunto de mecanismos, de prácticas que se dan al interior del campo y que legitiman la forma de capital jurídico que se posee de manera arbitraria. Es la imposición del capital jurídico mediante la negación, ocultación y dominación. Como afirma Bourdieu "Los efectos ideológicos más seguros son aquellos que, para ejercerse, no tienen necesidad de palabras, sino del laisser-faire y del silencio cómplice" (Bourdieu, 2007; 215).

En el interior del campo jurídico, al igual que en un campo de batalla, se desatan conflictos y competencias por las que los participantes pelean por establecer el monopolio sobre el tipo de capital efectivo dentro del campo y el poder para decretar la jerarquía entre todas las formas de autoridad en el campo de poder. Así, como explica Diego Eduardo López Medina:

"En el campo jurídico se enfrentan permanentemente concepciones sobre la forma de entender el derecho - praxis o teoría- y sobre cuáles deben ser los principios que deben regir el derecho en su conjunto, los del derecho privado, que se pretenden vinculados a la realidad social y a la economía, o los del derecho público, ordenados en una pretendida evolución de la sociedad hacia mayores niveles de justicia social" (Medina, 2010: 63).

En tal marco de contextualización histórico, me pregunto: ¿Cuál es la relación entre el neoliberalismo -forma del capitalismo ubicado en el campo ideológico político- y los diversos órdenes normativos constituyentes del campo jurídico en el período en estudio? ¿Puede la postura monopólica triunfante al interior del campo jurídico ser derivada de 
modo consistente de una forma histórica de constitución del campo político? ¿Qué clase de vínculos puede establecerse entre ambos campos? ¿Cómo repercuten las teorías jurídicas en la configuración económico política de la sociedad?

\section{Sostiene Bourdieu que:}

"hace falta tener en cuenta el conjunto de relaciones objetivas entre el campo jurídico, ligado a relaciones complejas y que obedecen a una lógica relativamente autónoma, y campo del poder, y, a través de él, con el campo social en su conjunto. Es al interior de este universo de relaciones que se definen los medios, los fines y los efectos específicos que le son asignados a la acción jurídica" (Bourdieu-Teubner, 2000: 203).

\section{El derecho administrativo argentino y su mirada a las relaciones de poder}

El derecho administrativo, parte integrante o sub-campo dentro del campo jurídico, se construye a partir de una mirada ideológica sobre las relaciones entre los individuos y el poder público, en el que se desequilibran derechos y potestades conformando un sistema llamado "Estado de Derecho".

Como ya vimos, en el interior del campo jurídico, al igual que en un campo de batalla, se desatan conflictos y competencias por las que los participantes pelean por establecer el monopolio sobre el tipo de capital efectivo dentro del campo y el poder para decretar la jerarquía entre todas las formas de autoridad en el campo de poder. En el campo jurídico se enfrentan en forma constante concepciones sobre la forma de entender el derecho, en su aspecto práctico y teórico, y sobre cuáles deben ser los principios que deben regir el derecho en su conjunto, los del derecho privado, que se pretenden vinculados a la realidad social y a la economía, o los del derecho público, ordenados en una pretendida evolución de la sociedad hacia mayores niveles de justicia social.

En el campo jurídico constituido por el derecho administrativo, tanto desde la doctrina, como desde la jurisprudencia no existe una expresa vinculación entre las teorías éticas de la justicia y la estructuración del derecho público en cuestión. Así, los grandes tratadistas generales del derecho administrativo argentino, como Rafael Bielsa (primer edición de su obra Derecho Administrativo data del año 1944), Benjamín Villegas Basavilbaso (su Tratado de Derecho Administrativo es de 1941), José Canasi (la primer edición de su Derecho Administrativo data de 1971), Manuel María Diez (Su obra Derecho Administrativo fue publicada en 1963) y Miguel Marienhoff (Su Tratado de Derecho Administrativo es del año 1965), que se desarrollaron y extendieron su influencia en la segunda mitad del siglo pasado no refieren a dichas posturas filosóficas de la justicia por ser anteriores o contemporáneos con el nacimiento de las obras de sus principales exponentes. En este primer grupo también incluyo las obras generales de los profesores de derecho administrativo, Francisco Linares y Bartolomé Fiorini.

Un segundo grupo destacado de autores que sucedieron a los grandes tratadistas, y cuyas obras exhibieron una relevancia central en el final del siglo pasado y el inicio del presente, si bien no desarrollaron una vinculación con las teorías de la justicia, sí evidenciaron una postura ideológica más expresa y manifiesta. Ejemplo de ello lo constituyen autores como Agustín Gordillo, Juan Carlos Cassagne, Rodolfo Carlos Barra y José Roberto Dromi, cuya doctrina ha sido durante estos años el contenido impartido en la materia derecho administrativo por universidades públicas y privadas en las que se formaron los profesionales del derecho que hoy actúan dentro del campo jurídico argentino. Estos agentes, titulares de capital cultural y también político, cumplieron funciones públicas de relevancia en las diversas etapas históricas en análisis (un ejemplo de ello lo constituye el paso de Rodolfo Barra como Ministro de la Corte Suprema de Justicia de la Nación, que José Roberto Dromi ocupara un el cargo de Ministro del Poder Ejecutivo y Juan Carlos Cassagne revistiera como Director de una empresa de Servicios Públicos, entre muchas otras actividades de relevancia política y social). 
Una especial referencia corresponde realizar a la tesis doctoral de Rodolfo Carlos Barra, luego publicada bajo el título "Principios de Derecho Administrativo" (1980) quien -desde una postura iusnaturalista- propone la construcción de las bases de la regulación jurídica a partir de la teoría de la justicia de Santo Tomás de Aquino.

Por último, el Tratado de Derecho Administrativo publicado por el profesor Carlos F. Balbín, al desarrollar las bases actuales del Derecho Administrativo, vincula los modelos del Estado Social y Democrático de Derecho y del Estado Neoliberal con la teoría y justificación del Estado. A diferencia de los doctrinarios antes citados, este autor, si bien lo hace en forma general y sin profundizar en el tema, destaca la importancia para el derecho administrativo de su enrolamiento en las diversas teorías políticas sobre la justicia (Balbín; 2011).

Afirma que;

"No nos proponemos en este contexto explicar las ideas de los autores clásicos [...] pero sí al menos señalar que actualmente existen distintas corrientes de pensamiento, entre ellas, el liberalismo conservador, el liberalismo igualitario y el comunitarismo y que, según nos enrolemos en unas u otras, la construcción dogmática del Derecho Administrativo es sustancialmente diferente" (Balbín, 2011; T.1, 37).

Describe luego en forma breve el autor las posturas libertarias (Nozick), liberales (Rawls) y comunitaristas. Respecto de las dos primeras sostiene que

"Quizás la distinción central entre estas dos corrientes de opinión dentro del liberalismo es el reconocimiento o rechazo de los derechos positivos y el papel del Estado. En este punto de nuestro razonamiento se advierte claramente cómo influyen estas Teorías en el contenido y alcance del desarrollo dogmático del Derecho Administrativo".

Respecto de las posturas comunitaristas afirma Balbín: "La discusión es evidentemente mucho más compleja pero el aspecto central-en el marco de nuestro conocimiento- es simplemente reflexionar sobre el vínculo entre la Teoría del Estado, Teoría de la Justicia y el Derecho Administrativo" (Balbín, 2011: T. 1, 38).

Veamos ahora, algunas líneas sobre el derecho administrativo argentino y su posicionamiento ideológico frente a la justicia distributiva.

Pasando ahora al sector del campo jurídico ocupado por el "Derecho Administrativo", relevaré superficialmente las posturas ideológicas (En este caso destacando el rol del estado y la justicia distributiva) de los autores contemporáneos más relevantes. Tal relevancia se encuentra determinada por la centralidad de su posición dentro del campo en estudio y la acumulación de diversos capitales que les permiten a estos doctrinarios decir que dice el derecho administrativo. Sus posiciones ideológicas -en muchos casosdieron contenido a concretas políticas públicas en las diversas etapas que se sucedieron en los últimos cuarenta años.

En líneas generales la doctrina administrativista referida propone al derecho administrativo como una herramienta de protección de los derechos individuales (libertad, propiedad) frente al Estado, postulando un equilibrio entre autoridad y libertad. Entiendo una pieza clave para desentrañar el sentido de justicia distributiva de la doctrina administrativista hegemónica es su posicionamiento frente a la posibilidad de efectivizar judicialmente los derechos económicos, sociales y culturales.

Por ejemplo, Agustín Gordillo, desde una de sus primeras obras ("Introducción al Derecho Administrativo", Editorial Perrot, Buenos Aires, 1962; "Tratado de Derecho Administrativo", Editorial Macchi, Buenos Aires, 1974) desarrolla un capítulo dedicado a las "Bases políticas, constitucionales y sociales del derecho administrativo". Allí, partiendo de definir al derecho administrativo como la rama del derecho público que estudia el ejercicio de la función administrativa y la protección judicial contra ésta, expone la oposición entre igualdad y libertad, articulados en posturas políticas e 
ideológicas sobre las cuales se construyeron dos modelos de estatalidad (Estado liberal de Derecho y Estado de Bienestar) proponiendo un equilibrio y complementariedad entre las garantías individuales y las garantías sociales.

Sobre la posibilidad de efectivización de los derechos sociales, cuestión que plantea en su tratado de derecho administrativo desde las primeras ediciones, se inclina por su carácter programático. Dice al respecto que; "Según la formulación que se les dé, tales derechos sociales podrán aparecer como auténticos derechos subjetivos de los habitantes, exigibles concretamente desde la misma sanción de la norma constitucional y sin necesidad de norma legislativa alguna que los reglamente, o podrán en cambio resultar meros derechos programáticos, normas de buen gobierno que carecen de efectividad real mientras los órganos legislativos o administrativos del Estado no deciden por su cuenta efectivizarlos", agregando como conclusión que "generalmente la enunciación constitucional de tales derechos tendrá un mero carácter programático, y no será el actual y real conferimiento al individuo de un derecho subjetivo..." (Gordillo; 1974: III-28).

Luego de la reforma constitucional de 1994, el Profesor Gordillo edita dos obras en las que abordó dos cuestiones de actualidad para el derecho administrativo de la década del noventa; los derechos humanos y la reforma del Estado. Sobre la cuestión de la efectivización de los derechos sociales, a la luz del nuevo texto constitucional y la incorporación de tratados internacionales de derechos humanos, el autor mantuvo su postura clásica, radicalizando su posición contraria a la posibilidad de judicializar los derechos sociales. Así sostuvo que;

"Nadie duda que es políticamente hermoso, hasta poéticamente atractivo, sostener que todo el mundo tiene derecho a tener satisfechas todas sus necesidades básicas en cualquier campo, sea él salud, vivienda, educación, cultura, progreso. Pero en esa fraseología se desliza un grave inconveniente: quienes así hablan o escriben se olvidan que han hecho un cambio de paso, y ya no están hablando de derecho como si fueran abogados o juristas, hombres del foro o de la justicia, profesores o estudiantes de derecho, sino que hablan de derecho como si fueran personas que desconocieran el significado técnico jurídico de la palabra en el ámbito forense. Es como si tal vez pensaran que la palabra puede usarse también para describir aspiraciones o pretensiones que no son susceptibles de ser llevadas con éxito ante un tribunal de justicia en parte alguna del mundo. Allí, obviamente quienes emplean de ese modo la palabra 'derecho' no hacen sino crear un mar de confusiones. Podrán fundarlo sin duda en consideraciones políticas, axiológicas, sociológicas, éticas, morales, religiosas, en principios universales; podrán invocar textos de carácter internacional que de algún modo u otro lo digan: pero lo cierto, lo concreto, es que no pueden ignorar que no pueden interponer una demanda contra el Estado y ganarla con ese planteamiento. No obtendrán sentencia favorable en ninguna instancia, perderán simplemente el juicio, al menos hoy por hoy. Es indispensable no crear en el joven alumno confusiones entre el derecho y otra ciencias sociales, o la política, o las aspiraciones, los sueños, los compromisos éticos, las obligaciones de solidaridad, etc." (Gordillo, 1997:VI-34).

En su obra "Después de la Reforma del Estado", Gordillo se refirió a la política de desregulación del mercado y de privatización de empresas y actividades estatales desarrolladas en la década del 90, compartiendo la necesidad de realizar tales transformaciones, aunque dejando sentada la necesidad de completar las reformas pendientes. Así dijo que:

"Ya a comienzos de la década del 80 los organismos en un cambio de orientación. Anticipaban el nuevo papel del Estado en el proceso económico y social. En poco tiempo más la crisis económica se transforma en crisis política, con el fin del gobierno soviético y el triunfo del libre mercado, la crisis del modelo burocrático, la sensación del fracaso de la empresa y en general la propiedad pública, privatizaciones por doquier. Desregulación desmonopolización, privatización, dejan de ser banderas políticas inglesas o norteamericanas, son políticas económicas mundiales, del Oeste y del Este, de las 
naciones y organismos multinacionales de los cuales depende nuestro crédito externo: 'las ideologías son más potentes que los Estados'. También en nuestro país, desde luego, se comenzó en esa década a postular la desregulación y a prestar atención a la protección del consumidor [...]. La reforma que venimos de explicar ha desarmado mucho del viejo aparato estatal, pero le ha faltado ajustar el resto a la nueva dinámica que ha creado. Corre con ello el riesgo de quedar claudicante frente a la nueva realidad que ha creado." (Gordillo, 1996; p. 1-25).

Juan Carlos Cassagne, por su parte, desde una postura iusnaturalista, declaró la muerte del Estado benefactor y el nacimiento del Estado Subsidiario, rechazando todo dirigismo estatal con fundamento en que la intervención del Estado debe regirse siempre por el principio de la suplencia o subsidiariedad;

"La quiebra del modelo que caracterizó al denominado Estado benefactor está a la vista de todos. La sociedad ya no acepta que el Estado intervenga activa y directamente en el campo económico-social asumiendo actividades que corresponde realizar a los particulares iure propio. El pretexto de la soberanía, la defensa nacional, la justicia social - la independencia económica, no sirven más como títulos que legitiman la injerencia estatal en las actividades industriales o comerciales, y, aún, en los servicios públicos que pueden ser prestados por particulares [...]. En síntesis, si el bien común que constituye el fin o causa final del Estado posee naturaleza subsidiaria y se encuentra subordinado al mantenimiento y al desarrollo de la dignidad de las personas que forman parte de la sociedad civil, el Estado no puede absorber y acaparar todas las iniciativas individuales y colectivas que se generan en el seno de aquélla. En otros términos, que la subsidiariedad es una obligada consecuencia de la propia naturaleza de la finalidad que el Estado persigue y el presupuesto indispensable para el ejercicio de las libertades del hombre" (Cassagne, 2008; T.1, 65).

Respecto de la justicia, adhiere a la postura de Santo Tomás de Aquino, en tanto la considera como el hábito según el cual uno, con constante y perpetua voluntad, da a cada cual su derecho. Para Cassagne, los alcances de la justicia distributiva respecto de cada persona debe ser valorada a la luz de criterios morales -calidad, aptitud o función de cada miembro del cuerpo social- para en base a ellos determinar la porción que la sociedad le debe a cada una de ellas. Así sostiene que

"El equilibrio de la doctrina sobre la justicia descansa en la subordinación de lo político, social, económico y jurídico a la moral y, en definitiva, en la perfección del hombre, sin la cual no pueden existir ni imponerse el orden y la paz, por la sencilla razón de que la comunidad no puede proporcionar lo que las partes integrantes no hubieran puesto en ella" (Cassagne, 2008: T. 1, 59).

Por otra parte se opone a aceptar que en el ámbito del derecho público exista una identificación con la justicia distributiva.

José Roberto Dromi, se enmarca en las posiciones generales descriptas respecto del régimen jurídico administrativo. Así sostiene que:

"El orden predica obligadamente el poder y el derecho. El orden se expresa en derecho y se organiza como poder, Poder y derecho son atributos esenciales, propios del orden, exigidos por la esencia del ser estatal. Luego, en su actuación, poder y derecho especificarán en la existencia una organización y un ordenamiento jurídico, público y administrativo de carácter básico, que explicite las relaciones fundamentales entre sociedad (Estado, autoridad, Administración) y persona (individuo, libertad, administrado)." (Dromi, 1987:7).

Rodolfo Barra defendió con éxito su tesis doctoral en la Facultad de Derecho de la Universidad Católica Argentina el 17 de marzo de 1980 bajo el título "El derecho administrativo como sistema de derecho público en el marco de la justicia distributiva". 
En junio del mismo año la tesis fue publicada, con prólogo de Juan Carlos Cassagne, bajo el título "Principios de derecho administrativo", contenido casi veinte años más tarde replicado en su primer tomo del "Tratado de Derecho Administrativo" (Barra,1998: T.1). El prologuista de su ópera prima afirmó que: "La aceptación de esa visión cristiana del derecho, concebido como el objeto de la justicia, con sus distintas especies, no implica, como bien se señala en la obra, que la sociedad de nuestros tiempos deba desatender el peligro que representa la ampliación progresiva de las competencias estatales, lo cual puede conducir a la despersonalización del hombre, sumergido en un proceso de socialización creciente, donde todo lo espera del Estado".

Así, Barra desarrolla en su obra las relaciones existentes entre los principios que rigen la justicia distributiva y las instituciones de derecho público y se propone

"la distinción radical entre el derecho público y el derecho privado, en función de las distintas especies de la virtud de la justicia y su relación con el bien común, como adecuado instrumento para una mejor comprensión del derecho administrativo [...]. En realidad, la base de este estudio, no pretende más que recordar las enseñanzas de la perenne filosofía tomista y de la moderna doctrina social pontificia, para aplicar sus conclusiones a una rama determinada de la ciencia jurídica" (Barra, 1980: 23).

Inicia el desarrollo de sus ideas sosteniendo la prevalencia del principio de subsidiariedad respecto de las funciones del sector público;

"por el cual la competencia del Estado alcanza sólo a aquellos ámbitos de la vida social en los que la actividad de los particulares -individuos o agrupaciones intermedias- no puede o no deba desarrollarse. La aplicación del principio de subsidiariedad importará regular los límites de las competencias estatales y, por consiguiente, fijar los alcances de todas las competencias sociales" (Barra, 1980: 37).

Si bien releva la aparición del Estado Social o de Bienestar, concluye a su respecto que

"Se nos presenta así una dramática paradoja: la extensión de las competencias estatales, respondiendo a una exigencia del bien común, puede significar la tumba de este mismo bien común por la importante cuota de socialización despersonalizante que trae aparejada" (Barra, 1980: 56).

Los orígenes del principio de subsidiariedad, defendido abiertamente tanto por Barra como Cassagne y aplicado por Dromi, se pueden encontrar en la teoría social de la iglesia (Encíclica Quadragesimo Anno; "toda actividad social es subsidiaria por esencia y su misma definición") y en la obra de Johannes Messner - referencia reiterada en la obra de Barra- para quien;

"El principio de subsidiariedad muestra que el bien común no es un fin en sí. El principio de subsidiariedad es por ello el principio social cristiano, que rechaza toda forma de independización colectivista (absolutización) de los fines sociales, del Estado de fuerza totalitario como del Estado de previsión socialista [...] El principio de subsidiariedad expresa la igualdad originaria de todos los derechos morales, de los del individuo y de los de las comunidades naturales: de las comunidades con finalidades fundadas en la naturaleza social humana". (Messner, 1960: 864)

Concluye en su tesis que el derecho público es el derecho del Estado en sí mismo y en sus relaciones con la sociedad aplicándose allí la virtud de la justicia distributiva, en la que:

"el reparto o asignación de prestaciones es autoritario y heterónomo. La entrega de la cosa debida no sólo es de interés para las partes de la relación específica. Lo es también comparativamente, para las partes de la relación virtual. Fundamentalmente, es de interés para el resto del cuerpo político, cuya subsistencia como tal depende de que en cada caso concreto se realice el bien común. Por ello la asignación de prestaciones es autoritaria, dado que requiere del ejercicio del poder estatal. Como tal asignación de 
prestaciones no depende de la voluntad de las partes, se afirma que el reparto es heterónomo, salvo que la derogación -la decisión de las partes de que a la hipótesis no se le aplique la consecuencia prevista en la norma- no perjudique a terceros (en especial al sujeto acreedor virtual) y se justifique en razones de interés público" (Barra, 1980:128).

Resulta interesante poder desarrollar las diversas vinculaciones y formas de relacionamiento entre estas construcciones teóricas propias del interior del campo jurídico (funciones del Estado, principio de subsidiaridad, justicia distributiva, inexigibilidad de los derechos sociales), por un lado con las ideologías políticas, filosóficas y éticas y por el otro con la realidad social sobre la que el derecho actúa. A modo de ejemplo se puede estudiar el modo en que el principio de subsidiariedad fue aplicado en el período 1976-1982, así como en la reforma del Estado puesta en marcha a mediados de la década del noventa. José Martínez de Hoz, en un opúsculo llamado "Bases para una Argentina Moderna -1976-80", expuso la aplicación del principio de subsidiariedad y las políticas de privatización de la dictadura militar que en esos años gobernó nuestro país. Allí dijo:

"El proceso de privatización que se inició a partir de 1976 revirtió una tendencia práctica y también filosófica favorable al estatismo...Es decir, el principio de subsidiariedad de la función del Estado no responde sólo a una formulación teórica, sino que proporciona el criterio para distribuir recursos limitados del Estado entre funciones prioritarias [...]. Entre las funciones del Estado que se definieron como parcialmente delegables 0 susceptibles de ejecución compartida con el sector privado, pueden mencionarse la prestación de servicios de educación, salud, seguridad social y algunos servicios públicos especiales y obras de infraestructura. Con respecto a las funciones de producción, se acordó que ellas en principio corresponden al sector privado y deben ser ajenas al Estado salvo casos muy excepcionales [...]. El programa de privatización requirió modificar innumerables disposiciones que establecían requisitos, no siempre justificados, para la venta de bienes públicos. Mediante el dictado de diversas normas se logró establecer una base jurídica que facilitara este proceso Esto llevó un cierto tiempo, pero el camino se ha abierto $y$, más allá de lo ya realizado en este aspecto durante nuestra gestión, la acción futura puede entonces ser mucho más ágil" (Martínez de Hoz, 1981: 48).

Finalmente, el Profesor Carlos F. Balbín, autor de "Curso de Derecho Administrativo" en dos tomos (2007) continuada por su "Tratado de Derecho Administrativo" en siete tomos (2011) propone una mirada diferente de la materia y postula la construcción de un nuevo paradigma del derecho administrativo superador de la clásica oposición entre poder (autoridad) y derecho (libertad). Afirma que el nuevo paradigma Derechos vs. Derechos es, "el equilibrio del poder entendido como el conjunto de prerrogativas que persiguen el reconocimiento de derechos versus otros derechos. Ese equilibrio entre derechos con intermediación del poder estatal y sus prerrogativas es el paradigma, entonces, del Derecho Administrativo actual. El derecho administrativo no debe pues analizarse desde el poder y sus prerrogativas sino desde los derechos fundamentales y estos últimos no sólo como límite de aquél sino como justificación del propio poder" (Balbín, 2011, T 1:173). En esa línea sostiene que si bien el derecho administrativo pudo ser entendido como un modelo de equilibrio entre poderes y derechos, "es necesario decir que el interés público es el interés definido por los representantes del Pueblo respetando las minorías y sus derechos y que su único fundamento es el reconocimiento de derechos". (Balbín, 2011: T1, 273).

Siguiendo el nuevo paradigma del derecho administrativo, Balbín se aparta de las posturas clásicas respecto de la posibilidad de exigir judicialmente la efectivización de los derechos sociales. Así sostiene que

"Los derechos sociales son operativos, plenamente exigibles, progresivos y, por último, interdependiente $\mathrm{e}$ indivisibles de los otros derechos [...] En este punto de nuestro análisis es posible concluir que el Estado debe satisfacer los derechos civiles y políticos e 
igualmente los derechos económicos, sociales y culturales" (Balbín, 2011: T 1, 135).

Recientemente publicó un trabajo doctrinario titulado "Un derecho Administrativo para la inclusión social", en el que sostiene que

"El Derecho Administrativo, en el marco del Estado Social y Democrático de Derecho, debe ser pensado como un derecho de inclusión y no sólo como un derecho de prevención y eventualmente reparación de los abusos o arbitrariedades estatales. El Doble Derecho satisface con mayor plenitud el reconocimiento de derechos en condiciones igualitarias porque el Derecho Privado persigue la recomposición de las desigualdades simplemente individuales y no las otras plurales y estructurales. Es necesario, por tanto, cambiar el paradigma, pero sobre todo el modo de pensar y construir el Derecho Administrativo" (Balbín; 2014).

V. Las ideas políticas y su vinculación con el campo jurídico en la Argentina contemporánea

En la Argentina -en los últimos 40 años- se han sucedido diversos modelos institucionales y políticos reflejos de determinadas posturas ideológicas, entre los que podemos identificar un período dictatorial neoliberal y conservador (1976-1983), seguido de una etapa de transición democrática con un estado benefactor (1983-1989), destacándose un posterior período neoliberal democrático conservador (1989-2003), seguido por una etapa democrática de Estado Social de Derecho caracterizada por un poder público interventor en los mercados y con políticas activas de inclusión social (2003-2015) y, finalmente el actual gobierno neoliberal y conservador (2015-Actualidad).

La incorporación -a través de la reforma constitucional del año 1994- de los principales tratados internacionales de Derechos Humanos revolucionó el sistema de fuentes de nuestro ordenamiento jurídico nacional impactando tanto en el derecho público como privado.

A partir de tal reforma se produjo al interior del campo jurídico una modificación sustantiva del sistema de fuentes por la cual se incorporaron normas internacionales de derechos humanos que reconocen expresamente un gran número de derechos sociales y plantean la posibilidad de su exigibilidad frente al Estado. Esta nueva constitución modificó las reglas de conductas del campo jurídico, determinando un cambio en lo que les está permitido hacer y lo que no lo está, a los agentes e instituciones jurídicas.

A pesar del nuevo texto constitucional la visión monopólica legitimada para interpretar el derecho, resistió el cambio y limitó los alcances y posibilidades de transformación de la nueva norma.

Paralelamente, en la misma década en que se reformó la Constitución, se impuso en nuestro país un modelo económico neoliberal que: disminuyó la intervención estatal, privatizó empresas públicas, desreguló los mercados, congeló el gasto público, flexibilizó la regulación legal de la relación laboral, redujo salarios y prestaciones sociales, aumentó geométricamente la deuda externa, cerró muchísimas fábricas nacionales, eliminó pequeñas y medianas empresas, suplantó la producción propia por importaciones y promovió la concentración económica en grandes empresas de capitales locales e internacionales. En los sucesivos gobiernos de Menem y De la Rúa se incrementó en forma considerable la cantidad de personas desempleadas y aumentó en igual modo la pobreza y la indigencia.

Esa política económica -similar a la impuesta en los países de nuestra región por el FMI y conocida como el Consenso de Washington- desconoció en los hechos todos los derechos sociales que se plasmaron en la nueva constitución reformada y generó en la población un desinterés por la participación política y un descreimiento en cualquier idea de transformación del sistema capitalista, adoptado ahora en su versión neoliberal. 
Este distanciamiento entre dos ámbitos de la realidad se expresó en que, por un lado el derecho formal -Constitución de 1994- constituyó nuevas situaciones jurídicas igualitarias e inclusivas, tanto en lo político (Democracia participativa) como en lo económico (Derechos sociales), y por otro, la estructura económico-social se caracterizó por un aumento de la pobreza y la desigualdad y una disminución de la participación política de la población, desconociendo de esta forma los avances establecidos en el texto constitucional reformado.

No obstante, las sucesivas crisis económicas y políticas provocaron la reacción de parte de la sociedad que acudió a la organización y a la lucha social, y además a las propias herramientas que el nuevo ordenamiento jurídico les brindaba para intervenir en modificaciones sectoriales mediante intervenciones legales (administrativas y judiciales).

Así, en los años sucesivos existieron crecientes prácticas concretas por las que actores y participantes del campo jurídico, con fundamento en la nueva Constitución, cuestionaron las reglas que distribuyen el poder al interior del propio campo. Grupos sociales, organizaciones no gubernamentales, partidos políticos, defensores públicos, abogados de interés público, funcionarios y autoridades políticas, jueces, profesores de derecho, iniciaron acciones judiciales, presentaron demandas, dictaron sentencias en las que se reconocía el derecho subjetivo de una persona o un grupo de ellas al efectivo goce de un derecho social (alimentación, vivienda, salud, etc.) ordenando al Estado a brindar la prestación en cuestión. Este conflicto o competencia por establecer el monopolio de decir el derecho dentro del campo jurídico, se ramificó afectando ya no sólo a los participantes en el juego, sino a las reglas por las cuales los participantes se regirán en el futuro al interior del campo.

A la crisis iniciada en los años 90 y cristalizada en el fatídico 2001, le siguieron doce años en los que el gobierno nacional adoptó políticas públicas propias del Estado de Bienestar, generando mecanismos de inclusión social, redimensionando el aparato estatal, interviniendo en los mercados con una finalidad redistributiva, reconociendo nuevos derechos a minorías o sectores vulnerables, regulando aspectos claves de la economía, teniendo como objetivo -logrado parcialmente- alcanzar un paulatino descenso de la desigualdad y construir un piso de justicia social. Esas políticas transformaron el campo jurídico, reconfigurando sus estructuras normativas en los diversos ámbitos en los que intervinieron.

En el recambio de gobierno del 2015 , asumió una propuesta política de centro derecha que instaló a través de sus políticas públicas un modelo de endeudamiento externo, apertura comercial, reducción de salarios y beneficios sociales, protección de los actores concentrados del mercado, y un abanico de acciones típicas de los gobiernos neoliberales caracterizada por un marcado retroceso en las políticas sociales y de reconocimiento de derechos construidas por el gobierno predecesor.

Hoy vivimos tiempos de judicialización de la política, de politización de la justicia, de lawfare, de litigio estratégico y juicios estructurales, de revisión judicial de políticas públicas, opositores políticos cautelarmente detenidos, y criminalización de los funcionarios que las llevaron a cabo en sus mandatos. En la arena político-mediática se puede ver a diario a ciudadanos de a pie, grupos sociales, movimientos religiosos, partidos políticos, legisladores -oficialistas y opositores-, dirigentes, gremialistas, ONGs, defensores del pueblo y al propio Estado, golpeando las puertas de tribunales para llevar a juicio una postura en la que -según alegan- se encuentra en juego el interés público de la sociedad, que -por supuesto- sólo ellos representan. Existe una evidente tensión entre los actores principales del campo político -que asumen una posición dominante y defienden una visión ideológica hoy hegemónica- y los representantes institucionales del Poder Judicial, hacia el interior del campo jurídico.

¿Cuál es la relación entre el campo de poder y el campo jurídico en el actual gobierno de la Alianza Cambiemos en la Argentina? 
Como vimos, el derecho es una construcción social que depende del momento histórico, de quiénes están detrás de esa construcción y de quienes son los constructores. A partir de ello, adelantaré dos intuiciones que pueden contribuir a encontrar una respuesta a dicha pregunta y de esa forma intentar comprender -dialécticamente- el fenómeno que aquí nos preocupa; existe una fuerte tensión en la relación del capitalismo neoliberal -hegemónico en el campo de poder- y el campo jurídico (mirada estructuralista), y un desacople entre los más altos representantes del Poder Ejecutivo y el Poder Judicial, posiblemente explicable - de un modo subjetivo- por la no pertenencia del presidente de la Nación (y de los principales referentes de su partido político) al campo jurídico (mirada constructivista). Veamos:

Fortich y Navarro (2012) estudiaron, utilizando el marco teórico de Bourdieu, el impacto del discurso neoliberal como pieza clave en la formación del campo jurídico latinoamericano. Afirman que las tendencias neoliberales de gobiernos presidencialistas se inclinan a buscar tecnócratas para ejercer el poder, con una visión muy gerencial, justamente,

"porque ese es el tipo de organización que propone el neoliberalismo: desmontar todo ese principio intervencionista del Estado dándole un vuelco a lo público y convirtiéndolo en privado, con un criterio unidimensional de las políticas públicas que tienen que ser verticales para poder tener mayor eficacia" (p. 58).

En esta lucha entre el neoliberalismo y la autonomía del campo jurídico, en Latinoamérica a principios de siglo, concluyen estos investigadores que el derecho se ve constantemente afectado y debilitado, y que "es un campo que no sirve para los presupuestos neoliberales" (Fortich y Navarro, 2012, p. 58). Esto puede explicar las políticas activas del gobierno argentino que desconocen muchos derechos reconocidos en el ordenamiento jurídico a vastos sectores de la población desfavorecida, así como las regulaciones jurídicas por las que el Estado intervino los diversos mercados y sectores de la economía.

La reacción del actual gobierno contra esta constelación de derechos sociales fue, por un lado atacar a la justicia laboral y a los abogados defensores de los trabajadores ${ }^{2}$, y por el otro lado desconocer las observaciones críticas de sectores de la sociedad civil y organismos internacionales de Derechos Humanos que luchan activamente por la defensa de derechos económicos, sociales y culturales. ${ }^{3}$

Mi primera intuición es que existe una dificultad en compatibilizar la ideología dominante en el campo de poder y la actual configuración del campo jurídico. El modelo económico político del Estado neoliberal construido bajo el sistema capitalista actual es incompatible con la efectivización de los Derechos Sociales reconocidos expresamente en el campo jurídico argentino. Es que, si bien el Estado debe contar con un margen de discreción en la elección de las políticas económicas a los fines de dar cumplimiento a las obligaciones asumidas en materia de derechos económicos y sociales, la adopción de un modelo económico neoliberal basado en el libre mercado, resulta incompatible con el sistema jurídico, con las obligaciones asumidas y con el concepto mismo de derechos sociales fundamentales.

Además de la relación del neoliberalismo y el campo jurídico (abordaje objetivo o estructuralista perteneciente a los campos), podemos analizar -haciendo foco desde el subjetivismo en la voluntad de los principales actores del campo de poder- que los actuales titulares de los poderes ejecutivo nacional y de varias provincias gobernadas por la Alianza Cambiemos, no pertenecen al campo jurídico, como: el Presidente de la Nación (Ingeniero Mauricio Macri), y los gobernadores de Buenos Aires (Licenciada en Ciencias Políticas María Eugenia Vidal), Jujuy (Contador público Gerardo Morales), Mendoza (Licenciado en Ciencias Políticas Alfredo Cornejo), Ciudad Autónoma de Buenos Aires (Licenciado en Economía Rodríguez Larreta). Este último abordaje constructivista nos impone analizar el concepto de habitus aplicado al campo jurídico en el contexto histórico político en estudio. 
En un sistema institucional presidencialista como el nuestro, resulta relevante del rol de las cabezas que ocupan los máximos cargos de los poderes ejecutivos. Tradicionalmente los presidentes pertenecían a la categoría juristas, habiendo adquirido los habitus del campo jurídico. Desde el retorno a la democracia, todos los presidentes detentaron el título de abogados (Alfonsín, Menen, De la Rúa, Duhalde, Kirchner y Fernández) y por lo tanto, probablemente, se encontraron alcanzados por el efecto de ilusión antes descripto. Ello implicó que se encontraran alcanzados por las limitaciones del propio campo al que pertenecían, es decir, constreñidos por ese espacio de posibilidades y también de imposibilidades, quedando atrapados en dicho juego y por sus reglas.

A diferencia de sus predecesores inmediatos, el actual presidente (y la mayoría de los altos funcionarios y actores políticos relevantes del partido gobernante) no pertenece al campo jurídico. Proviene del campo empresarial, que tiene su propia estructura y reglas y requiere de un determinado habitus, que se diferencia de las regulaciones del campo jurídico.

Las declaraciones y muchas medidas políticas adoptadas por el titular del Poder Ejecutivo nacional muestran esta extrañeza respecto del habitus de los actores del campo jurídico y de las reglas de su funcionamiento.

Su postura institucional sobre la relación del Poder Ejecutivo y el Poder Judicial se aparta de los parámetros propios del campo jurídico donde ambas estructuras construyen sus competencias y donde se delimita las posibilidades de actuación de cada uno.

El presidente argentino actual carece de la illusio que comparten sus predecesores inmediatos desde la recuperación de la democracia, y esto es un fenómeno novedoso que debemos abordar con mayor profundidad que la aquí posible.

Intuyo además que esto puede ayudarnos a interpretar algunas conductas, decisiones o declaraciones del propio presidente de la Nación que lo ubican traspasando reglas propias del campo jurídico y transgrediendo el espacio de posibilidades e imposibilidades que le impone el derecho. Veamos algunos ejemplos; dijo Macri: "Ios jueces tienen que saber que buscamos la verdad o buscaremos otros jueces que nos representen", o la afirmación pública, en referencia al procesamiento judicial y detención de una dirigente social, en la que sostuvo que "a la mayoría de los argentinos nos ha parecido que había una cantidad de delitos importantes que había cometido Milagro Sala, que ameritaban todas esas causas que tiene abiertas. Pero es importante que esa información y este entendimiento sea compartida por todo el mundo" ${ }^{4}$. La decisión institucional que más evidencia el tipo de relación entre los poderes políticos y el judicial que tiene el presidente, fue la designación de magistrados de la Corte Suprema de Justicia de la Nación, sin el acuerdo del Senado exigido constitucionalmente, medida que tuvo que dejar de lado por la presión social y la reacción de muchos y destacados miembros del campo jurídico.

Como ultima ejemplificación recurro a una intervención específica dentro del campo jurídico, recientemente llevada a cabo por las máximas autoridades de la nación con competencia para demandar ante el Poder Judicial. El gobierno nacional inició una acción judicial para intentar bloquear medidas cautelares contra el aumento de las tarifas y denunció al Centro de Estudios para la Promoción de la Igualdad y la Solidaridad (CEPIS) por su intento destinado a frenar el último aumento del gas. Pero no solo eso, sino también incluye a todas las organizaciones. Las presentaciones las realizó el ministro de Medio Ambiente, Sergio Bergman, con el patrocinio del Procurador del Tesoro, Bernardo Saravia Frías. El objetivo principal es frenar a CEPIS y a "cualquier otra asociación, organizaciones e individuos, y hasta solicitudes cautelares de las primeras, requiriendo interrumpir la ejecutoriedad de la política energética y ambiental del Poder Ejecutivo Nacional que intente poner en cuestión la política tarifaria". El gobierno expuso -en esta atípica acción- como argumento principal que el aumento de las tarifas es de interés público porque favorece el ahorro de energía, la eficiencia energética y el cuidado del medio ambiente. Resulta otro claro ejemplo de apartamiento de la práctica judicial del 
Estado durante décadas, que evidencia una comprensión del fenómeno jurídico que se aparta de los estándares tradicionales.

Este desacople entre parte hegemónica del campo de poder y el campo jurídico puede repercutir en las funciones legitimadoras del derecho respecto del sistema económico ideológico que prima en nuestro espacio social en este momento. Bourdieu explica que:

"El derecho, forma por excelencia del discurso legítimo, no puede ejercer su eficacia específica sino en la medida que obtiene reconocimiento, en la medida en que se desconoce la parte más o menos grande de arbitrariedad que está en el origen de su funcionamiento. La creencia en el orden jurídico, tácitamente convenida, debe ser reproducida sin cesar y es una de las funciones del trabajo propiamente jurídico de codificación de las representaciones y de las prácticas éticas la de contribuir a fundar la adhesión de los profanos a los fundamentos mismos de la ideología profesional del cuerpo de juristas, es decir, a la creencia en la neutralidad y en la autonomía del derecho y de los juristas" (Bourdieu y Teubner, 2000, p. 207).

Si desde el campo de poder, sus principales actores políticos y económicos desconocen el funcionamiento interno del propio sistema jurídico, sin considerar en su accionar sus normas, doctrinas, jurisprudencia y teorías, ya sea porque se defiende una ideología -neoliberalismo- que no se adapta al actual ordenamiento jurídico (en el que se reconocen expresamente derechos económicos, sociales y culturales, obligando a una intervención activa del Estado en la economía, limitando la pretendida libertad del mercado) y no pueden suplantarlo por otro, o porque no pertenecen al campo jurídico ni participan del habitus, ni comparten la illusio con el resto de la comunidad de juristas, se corre el riesgo de tensionar irracionalmente su vínculo con el campo jurídico debilitando el Estado de Derecho y el sistema democrático.

\section{Síntesis}

En el presente trabajo se intentó aportar una mirada que desde la sociología enriquezca el tradicional abordaje jurídico de un fenómeno que extiende sus consecuencias a la realidad social de toda la comunidad, superando los umbrales que delimitan el propio campo jurídico. Maniobras mediáticas y judiciales como las aquí descriptas, bajo apariencias de legalidad y de justicia, lesionan seriamente la calidad democrática en nuestros países, entendiendo que semejante fenómeno pone en crisis al propio Estado de Derecho y al sistema jurídico sobre el que se sostiene.

Situaciones similares se pueden observar en varios países de nuestra región y es una realidad que nos impone reflexionar sobre la relación entre las formas actuales de configuración del poder real (político, económico, mediático), las formas de su conformación hegemónica y los campos de poder y campo jurídico.

Existe una relación entre lo político y la pluralidad de órdenes normativos existentes -en el caso derecho en general y en particular el administrativo argentino-. La transición entre las posturas ideológicas sobre la justicia distributiva y el ordenamiento normativo que estructura el campo jurídico no presupone una estricta yuxtaposición entre ambos. De ello se deriva la dimensión de simultánea autonomía heterónoma que constituye necesariamente el orden legal que estructura el campo jurídico. El análisis del impacto que conflictos como el lawfare imparten en el campo jurídico deben ser abordados con la doble mirada -interna y externa- que propone Bourdieu.

En las últimas décadas la valoración social sobre el rol de los medios de comunicación y la imparcialidad de las empresas periodísticas entraron en crisis, corriéndose el velo que ocultaba las redes de poder y los intereses económicos detrás de grandes emporios de la comunicación. Hoy vivimos una crisis similar en la que ya pocos creen ni en la independencia judicial ni en la imparcialidad de los jueces. Cómo regular democráticamente -desactivando los efectos nocivos de la intervención del poder 
económico concentrado-, tanto el Poder Judicial como los medios masivos de comunicación, es el gran desafío que como sociedad tenemos por delante.

Bibliografía

BALBÍN, C. F. Tratado de Derecho Administrativo. Editorial La Ley: Buenos Aires, 2011.

BALBÍN, C. F. Un derecho administrativo para la inclusión social. Diario La Ley, 28.05.2014.

BARRA, R. C. Principios de derecho administrativo. Editorial Abaco de Rodolfo Depalma: Buenos Aires, 1980.

BARRA, R. C. Tratado de Derecho Administrativo. Editorial Abaco de Rodolfo Depalma, Buenos Aires, 2002.

BOURDIEU, P. "Los juristas, guardianes de la hipocresía colectiva". [www.pensamientopenal.com.ar/system/files/2016/08/doctrina43967.pdf]. 2006.

BOURDIEU, P. Poder. Derecho y Clases Sociales. Bilbao: Ediciones Desclée, 2001.

BOURDIEU, P. y Teubner, G. "La Fuerza del Derecho". Bogotá: Ediciones Uniandes, 2001.

CABRAL, P. El Convenio Colectivo para los Docentes de las Instituciones Universitarias Nacionales y su plena vigencia en la Facultad de Ciencias Jurídicas y Sociales de la UNLP. Derechos En Acción, (3). [https://doi.org/10.24215/25251678e013]. 2017.

CASSAGNE, J. C. Derecho Administrativo. Abeledo Perrot: Buenos Aires, 2008.

CHIHU, A. La teoría de los campos en Pierre Bourdieu. Revista Polis, México, UNAM, 1998.

COLANTUONO, P. Ángel G. Legalidades aparentes. Derechos En Acción, 7(7). [ https://doi.org/10.24215/25251678e166]. 2018.

DROMI, J. R. Manual de derecho administrativo. Editorial Astrea: Buenos Aires, 1987.

FERREIRA DA ROCHA, S. L. El Juez, la construcción de los hechos y el estado de excepción: un análisis del caso Lula. Derechos En Acción, 7(7). [ https://doi.org/10.24215/25251678e168]. 2018.

FORTICH, M. P; MORENO, A. Elementos de la teoría de los campos de Pierre Bourdieu para una aproximación al derecho en América Latina: consideraciones previas. 2012.

GORDILLO, A. Tratado de Derecho Administrativo. Ediciones Macchi S.A.: Buenos Aires, 1974.

GORDILLO, A. Derechos Humanos. Fundación de Derecho Administrativo: Buenos Aires, 1997.

GORDILLO, A. Después de la Reforma del Estado. Fundación de Derecho Administrativo: Buenos Aires, 1966.

Pierre Bourdieu para una aproximación al derecho en América Latina: Consideraciones previas. Verba Juris 27, Bogotá.

Martínez de Hoz, J. A. Bases para una Argentina Moderna 1976-80. Compañía Impresora Argentina S.A.: Buenos Aires, 1981.

Medici, A. Articulación de docencia-investigación extensión para una práctica pedagógica 
crítica en la enseñanza de los Derechos Humanos. Derechos En Acción, 7(7). [https://doi.org/10.24215/25251678e147]. 2018.

Messner, J. La cuestión Social. Ediciones RIALP SA: Madrid, 1960.

Moreno, G. R. El Poder Judicial como arma política. Sobre la intervención judicial del partido justicialista en la República Argentina. Derechos En Acción, 7(7). [https://doi.org/10.24215/25251678e164]. 2018.

Raimundi, C., \& Galarza, E. (2018). Política y corrupción. Nuevo capítulo de la batalla cultural. Derechos En Acción, 7(7). [https://doi.org/10.24215/25251678e165].

Valim, R. (2018). Estado de excepción. La forma jurídica del neoliberalismo. Derechos En Acción, 7(7). [https://doi.org/10.24215/25251678e167].

Sumário:

1 A fines de la década de los 90 'surge el término en ingles Lawfare, que lo podríamostraducir como "guerra legal" o "guerra jurídica". Es decir, una táctica que consiste en utilizar la ley como arma de guerra. El término apareció por primera vez en un trabajo del General de División retirado Charles Dunlap Jr., de la Fuerza Aérea de los Estados Unidos, en el año 2001 y desde ese momento se lo identifica con el uso abusivo de las leyes y sistemas judiciales para el logro de objetivos militares y políticos. Para el profesor Gregory P. Noonee, Director del Programa de Seguridad Nacional e Inteligencia en Fairmont State Universe, la guerra jurídica es "un arma diseñada para destruir al enemigo mediante el uso, mal uso y abuso del sistema legal y los medios de comunicación para provocar protestas públicas contra ese enemigo".

2 Diario Página 12, Buenos Aires, 26.07.2016, nota: Mauricio Macri reclamó que la justicia laboral falle menos para los trabajadores y más para los empresarios. Justicia laboral o justicia patronal: "El mandatario consideró que, para que lleguen las ansiadas inversiones, hace falta 'una justicia laboral más equitativa, no tan volcada a encontrarle siempre la razón a una parte'. El Presidente también fustigó a los jueces que 'obstaculizan' su gestión (por ejemplo, frenando el aumento de tarifas) y responsabilizó a Justicia Legítima." Ver también, Diario Página 12, Buenos Aires, 13 de junio de 2017, nota: Mientras los camaristas defienden la independencia judicial. Macri contra los jueces laborales, en la que se lee: "El Presidente utilizó nada menos que la jura del nuevo canciller pararedoblar su agresión contra el fuero laboral [...]. De momento los embajadores extranjeros acreditados aquí escucharon cómo cargaba contra abogados que "convencen a los trabajadores de hacer un juicio indebido y se lo hacen ganar porque tienen armadita la cosa para llevarse la mayor parte del juicio ellos". "Este grupo de estudios laboralistas, que por suerte son una minoría, con un grupo de jueces, minoritario, laboralistas, conducido por Recalde, le han hecho mucho daño a la Argentina", dijo Macri. "[...] Macri dijo que los juicios laborales 'dejan a un montón de gente sin acceder a un trabajo porque el que tien' que tomar decisiones tiene miedo de que su esfuerzo se le vaya en uno de estos comportamientos mafiosos".

3 Diario La Nación, Buenos Aires, 8.12.2014; Declaraciones de Mauricio Macri:

"Conmigose acaban los curros en derechos humanos".

4 La decisión de la justicia de Jujuy de mantener detenida a Milagro Sala fue recriminadapor la Organización de Naciones Unidas (ONU), la Organización de Estados Americanos (OEA) y la Comisión Interamericana de Derechos Humanos (CIDH). 